\title{
PERAN PERAWAT DAN BIDAN TERHADAP PELAKSANAAN INISIASI MENYUSU DINI (IMD)
}

\author{
Bekti Sukoco ${ }^{1}$, Endah Purwanti ${ }^{2}$, Ade Ragil Agung Wibowo ${ }^{3}$, \\ Devvyta Ferika Sari ${ }^{4}$ \\ Politeknik Kesehatan Kementerian Kesehatan Jayapura ${ }^{1,2,3,4}$ \\ bestika1@yahoo.com ${ }^{1}$
}

\begin{abstract}
ABSTRAK
Penelitian ini bertujuan untuk melihat bagaimana peran petugas terhadap pelaksanaan inisiasi menyusu dini (IMD) dan cakupan IMD pada bayi baru lahir. Metode yang digunakan adalah kuantitatif dengan pendekatan analisis deskriptif. Hasil penelitian menunjukkan bahwa peran perawat dan bidan terhadap pelaksanaan IMD termasuk dalam kategori dengan rerata skor adalah 95,39. Angka keberhasilan IMD juga termasuk dalam kategori tinggi dengan rerata skor 93,75. Simpulan, peran perawat dan bidan terhadap pelaksanaan IMD termasuk dalam kategori baik dan keberhasilan IMD juga termasuk dalam kategori tinggi.
\end{abstract}

Kata Kunci: Air Susu Ibu, Inisiasi Menyusu Dini, Peran Perawat dan Bidan

\begin{abstract}
This study aims to see how the role of officers in the implementation of early initiation of breastfeeding (IMD) and coverage of IMD in newborns. The method used is quantitative with a descriptive analysis approach. The results showed that the role of nurses and midwives in the implementation of IMD was included in the category with the mean score of 95.39. The IMD success rate is also included in the high category with an average score of 93.75. In conclusion, the role of nurses and midwives in the implementation of IMD is in the good category and the success of IMD is also in the high category.
\end{abstract}

Keywords: Mother's Milk, Early Initiation of Breastfeeding, Role of Nurses and Midwives

\section{PENDAHULUAN}

Air susu ibu (ASI) memiliki banyak manfaat karena mengandung semua gizi yang dibutuhkan bayi untuk enam bulan pertama kehidupan. Diantaranya adalah mencegah diare, pneumonia, dan obesitas saat kanak-kanak dan remaja. Menyusui pada bayi adalah nutrisi yang paling efektif untuk menjaga kesehatan dan harapan hidup anak karena memiliki banyak manfaat karena mengandung semua gizi yang dibutuhkan bayi untuk enam bulan pertama kehidupan, diantaranya adalah mencegah diare, pneumonia, dan obesitas saat kanak-kanak dan remaja (WHO, 2019). Karena pentingnya ASI, maka WHO membuat rekomendasi, yaitu: ibu menginisiasi untuk menyusui dalam satu jam pertama, bayi harus mendapatkan ASI eksklusif sampai enam bulan agar pertumbuhan dan perkembangannya optimal, dan ASI harus dipertahankan sampai usia dua tahun (WHO, 2018). 
Inisiasi menyusu dini (IMD) adalah tercapainya pemberian ASI kepada bayi dalam satu jam pertama dan memastikan bahwa bayi mendapatkan kolostrum yang dapat melindungi bayi dari penyakit (Mugadza et al., 2017; WHO, 2019). IMD memiliki banyak manfaat untuk bayi, di antaranya adalah mencegah infeksi, mencegah diare, dan menambah angka harapan hidup anak karena dapat mencegah kematian pada neonatus (Abie \& Goshu, 2019). Dalam suatu studi menunjukan bahwa IMD dapat mencegah kematian bayi sampai angka 33\% (Mugadza et al., 2017). Terlambatnya IMD dapat meningkatkan angka kesakitan dan kematian bayi. Dalam studi yang dilakukan secara systematic review, bayi yang diberi ASI di bawah satu jam pertama kelahiran lebih kecil resiko kematiannya daripada yang diberikan setelah dua jam (Smith et al., 2017).

Mengingat pentingnya IMD, maka WHO membuat beberapa rekomendasi, yaitu: 1) kontak kulit ke kulit antara ibu dan bayi harus segera difasilitasi dan didorong secepat mungkin setelah kelahiran, 2) semua ibu harus didukung untuk IMD segera setelah lahir sampai satu jam pertama, 3) ibu harus mendapat dukungan pelatihan agar dapat melakukan IMD dan memberikan ASI dan mengatasi kesulitan yang umum terjadi (WHO, 2017). Menurut WHO, tiga dari lima ibu tidak melakukan IMD (WHO, 2018). Di Indonesia sendiri cakupan IMD pada tahun 2018 adalah 58,2\%, walaupun terjadi peningkatan dari tahun-tahun sebelumnya, namun masih jauh dari target $80 \%$ (Balitbangkes, 2019).

Untuk tercapai IMD, maka banyak faktor-faktor yang mempengaruhinya, di antaranya adalah petugas (pengetahuan dan sikapnya), pengetahuan dan sikap ibu tentang IMD, sarana kesehatan, dan dukungan keluarga (Fitriana, 2017; Irama \& Muhartati, 2018; Kaban, 2018; Mujur et al., 2019; Siahaan \& Panjaitan, 2020; Sulistianingsih, 2020). Dalam penelitian lain yang dilakukan secara cross-sectional, bahwa yang mempengaruhi keberhasilan IMD secara signifikan adalah kontak kulit ke kulit, cara melahirkan dan alat bantu yang digunakan untuk melahirkan (Gayatri \& Dasvarma, 2020). Beberapa penelitian menemukan bahwa status paritas ibu berpengaruh terhadap keberhasilan IMD (Ruhayati et al., 2019; Gayatri \& Dasvarma, 2020). Penelitian yang dilakukan oleh Adewuyi et al (2017) bahwa keberhasilan IMD di daerah perkotaan lebih tinggi daripada daerah pedesaan. Penelitian lain secara scoping review ditemukan bahwa faktor-faktor penghambat IMD adalah operasi caesar, nyeri paska persalinan, masalah laktasi dan komplikasi kehamilan, faktor sosial dan demografi, rendahnya dukungan ibu, kondisi bayi, sedangkan yang menunjang IMD adalah perilaku positif ibu terkait tingkat pendidikan, perawatan antenatal yang lengkap, ekonomi ibu, dan ukuran bayi (Hadisuyatmana et al., 2021).

Penelitian yang dilakukan secara kualitatif ditemukan bahwa peran petugas terhadap pelaksanaan IMD masih belum optimal yang dikarenakan kurangnya pengetahuan petugas, motivasi petugas, dukungan atasan terkait supervisi dan tidak tersedianya media informasi (Indra \& Ruswanti, 2017; Sukarti et al., 2020).

Penelitian tentang peran petugas ini sudah pernah dilakukan oleh, namun respondennya adalah petugas itu sendiri dan dilakukan secara kualitatif dengan wawancara mendalam. Untuk mendapatkan data secara objektif, maka dalam penelitian ini dilakukan secara kuantitatif dan respondennya adalah ibu yang pernah melahirkan dan ditangani oleh perawat/bidan dari saat hamil sampai melahirkan. 


\section{METODE PENELITIAN}

Penelitian ini merupakan jenis penelitian kuantitatif dengan pendekatan analisis deskriptif. Penelitian ini dilakukan di wilayah kerja Puskesmas Distrik Kurik Kabupaten Merauke Provinsi Papua. Waktu penelitian akan dilaksanakan pada tahun 2020.

Populasi dalam penelitian ini adalah ibu-ibu yang memiliki bayi usia 0-6 bulan di wilayah kerja Puskesmas Distrik Kurik Kabupaten Merauke yang berjumlah 40 orang melalui teknik sampling total setelah melalui kreteria inklusi dan eksklusi.

Alat ukur yang digunakan untuk mengumpulkan data tentang peran perawat dan bidan terhadap pelaksanaan inisiasi menyusu dini adalah berupa daftar pertanyaan dalam bentuk kuesioner. Kuesioner yang berisi tentang peran perawat dan bidan sebanyak 13 pertanyaan dan keberhasilan IMD sebanyak 10 pertanyaan. Pertanyaan yang diberikan berupa pertanyaan tertutup dan dijawab langsung oleh responden tanpa diwakilkan kepada orang lain.

Jumlah pertanyaan dalam kuesioner peran perawat dan bidan ini ada 13 item pertanyaan. Penentuan skor untuk kuesioner peran perawat dan bidan menggunakan skala Guttman yaitu skala yang menginginkan jawaban tegas (ya-tidak), dengan pemberian nilai sebagai berikut : untuk jawaban positif diberi skor 1 sedangkan untuk jawaban negative diberi skor 0 . Setelah dilakukan uji validitas dan reliabilitas, instrumen dinyatakan valid dan reliabel.

Analisis untuk penelitian ini menggunakan statistik deskriptif data dari variabel peran perawat dan bidan menggunakan parameter yang dibagi menjadi tiga kategori yaitu, peran petugas baik, sedang dan rendah. Hal ini dilakukan dengan cara mencari skor tertinggi dan skor terendah terlebih dahulu, yaitu dengan mengalikan skor dari jawaban dengan jumlah item yang ada. Kuesioner terdiri atas 13 item pertanyaan untuk peran perawat dan bidan, 10 item pertanyaan untuk keberhasilan IMD yang setiap itemnya diberi skor 1 untuk jawaban positif, dan skor 0 untuk jawaban negatif.

Seluruh proses analisis data menggunakan bantuan perangkat lunak komputer PSPP, yaitu perangkat lunak bersifat open source untuk menganalisis data secara statistik, dengan cara membaca dan menganalisis data dan menampilkan hasil.

\section{HASIL PENELITIAN}

\section{Karakteristik Responden Berdasarkan Umur Ibu}

Tabel. 1

Karakteristik Responden Berdasarkan Umur

\begin{tabular}{llcc}
\hline No & Kelompok Umur & Jumlah & Persentase $(\%)$ \\
\hline 1 & $18-25$ & 10 & 25 \\
2 & $26-30$ & 14 & 35 \\
3 & $31-35$ & 9 & 22.5 \\
4 & $36-41$ & 7 & 17.5 \\
\hline & Total & 40 & 100 \\
\hline
\end{tabular}

Berdasarkan tabel 1 diketahui bahwa kelompok umur terbesar adalah 26-30 tahun dengan jumlah 14 atau 35\%. Ini menandakan sebagian besar responden berada dalam rentang puncak usia subur. 


\section{Karakteristik Responden Berdasarkan Umur Bayi}

Tabel. 2

Karakteristik Responden Berdasarkan Umur Bayi

\begin{tabular}{llcc}
\hline No & Kelompok Umur & Jumlah & Persentase (\%) \\
\hline 1 & $0-12$ minggu & 20 & 50 \\
2 & $13-24$ minggu & 20 & 50 \\
\hline \multicolumn{2}{l}{ Total } & 40 & 100 \\
\hline
\end{tabular}

Berdasarkan data pada tabel 2 diketahui bahwa jumlah pada setiap kelompok umur bayi yang dimilik responden adalah sama.

\section{Karakteristik Responden Berdasarkan Pendidikan}

Tabel. 3

Karakteristik Responden

Berdasarkan Pendidikan

\begin{tabular}{llcc}
\hline No & Pendidikan & Jumlah & Persentase $(\%)$ \\
\hline 1 & SD & 5 & 12.5 \\
2 & SMP & 13 & 32.5 \\
3 & SMA & 15 & 37.5 \\
4 & PT & 7 & 17.5 \\
\hline & Total & 40 & 100 \\
\hline
\end{tabular}

Berdasarkan tabel 3 menunjukkan bahwa tingkat pendidikan responden yang terbanyak adalah SMA yaitu sebesar 37,5\%.

\section{Karakteristik Responden Berdasarkan Pekerjaan}

Tabel. 4

Karakteristik Responden

Berdasarkan Pekerjaan

\begin{tabular}{llcc}
\hline No & \multicolumn{1}{c}{ Pekerjaan } & Jumlah & Persentase $(\%)$ \\
\hline 1 & Pedagang/wirausaha & 4 & 10 \\
2 & Buruh/tani & 5 & 12.5 \\
3 & PNS & 0 & 0 \\
4 & TNI/Polri & 0 & 0 \\
5 & Pensiunan & 0 & 0 \\
6 & Pegawai swasta & 2 & 5 \\
7 & Ibu rumah tangga & 29 & 72.5 \\
\hline & Total & 40 & 100 \\
\hline
\end{tabular}

Berdasarkan tabel 4 menunjukkan bahwa pekerjaan responden yang terbanyak adalah ibu rumah tangga atau tidak bekerja, yaitu sebesar 72,5\%. 


\section{Peran Perawat dan Bidan terhadap Pelaksanaan IMD}

Tabel. 5

Skor Peran Perawat dan Bidan terhadap Pelaksanaan IMD

\begin{tabular}{clcc}
\hline No & Skor & Jumlah & Persentase (\%) \\
\hline 1 & 54 & 3 & 7.5 \\
2 & 85 & 2 & 5 \\
3 & 92 & 2 & 5 \\
4 & 100 & 33 & 82.5 \\
\hline Total & Rerata: 95.39 & 40 & 100 \\
\hline
\end{tabular}

Berdasarkan tabel 5 diketahui bahwa skor dengan jumlah terbanyak adalah 100, yaitu sebesar $82,5 \%$ dan rerata skornya adalah 95.39. Oleh karena itu peran perawat dan bidan terhadap pelaksanaan IMD sudah baik.

\section{Keberhasilan IMD}

Tabel. 6

Skor Keberhasilan IMD

\begin{tabular}{clcc}
\hline No & Skor & Jumlah & Persentase (\%) \\
\hline 1 & 40 & 2 & 5.0 \\
2 & 50 & 1 & 2.5 \\
3 & 60 & 1 & 2.5 \\
4 & 80 & 1 & 2.5 \\
5 & 90 & 2 & 5.0 \\
6 & 100 & 33 & 82.5 \\
\hline Total & Rerata: 93.75 & 40 & 100 \\
\hline
\end{tabular}

Berdasarkan tabel 6 diketahui bahwa skor dengan jumlah terbanyak adalah 100, yaitu sebesar $82,5 \%$ dan rerata skornya adalah 93.75. Oleh karena itu tingkat keberhasilan IMD sudah tinggi.

\section{PEMBAHASAN}

\section{Karakteristik Responden Berdasarkan Umur Ibu}

Jika dilihat pada tabel 3, bahwa pendidikan responden yang terbanyak adalah SMA. Hal ini sedikit berbeda dengan hasil survei yang dilaporkan oleh Kementerian Pemberdayaan Perempuan dan Perlindungan Anak RI bekerjasama dengan Badan Pusat Statistik, bahwa perempuan di pedesaan dengan pendidikan terbanyak adalah SD yaitu sebesar 59,06\%, sedangkan yang berpendidikan SMA ke atas lebih sedikit, yaitu sebesar 23,84\%, dan selebihnya adalah berpendidikan SMP (Kemenpppa, 2019).

\section{Karakteristik Responden Berdasarkan Pekerjaan}

Jika dilihat pada tabel 4, bahwa sebagian besar responden tidak bekerja atau hanya sebagai ibu rumah tangga. Hal ini sejalan dengan laporan hasil survei oleh Kementerian Pemberdayaan Perempuan dan Perlindungan Anak RI bekerjasama dengan Badan Pusat Statistik, bahwa perempuan di perdesaan yang yang bekerja sebagai ibu rumah tangga di seluruh Indonesia memiliki persentase yang paling besar yaitu 34.58\% (Kemenpppa, 2019). 


\section{Peran Perawat dan Bidan terhadap Pelaksanaan IMD}

Jika dilihat pada tabel 5 terlihat bahwa peran perawat dan bidan terhadap pelaksanaan IMD dalam kategori baik. Hal ini sejalan dengan pentingnya peran petugas sebagai care giver tehadap keberhasilan IMD (Fitriana, 2017; Irama, \& Muhartati, 2018; Kaban, 2018; Kumalasari et al., 2019; Mujur et al., 2019; Yuliea, 2019; Siahaan \& Panjaitan, 2020; Sulistianingsih, 2020). Namun penelitian yang lain menunjukkan hasil yang berbeda, yaitu peran petugas terhadap IMD belum optimal (Indra and Ruswanti, 2017; Sukarti, Windiani and Kurniati, 2020). Penelitiaan lain menunjukkan bahwa tidak ada hubungan antara peran petugas dengan keberhasilan IMD (Warsini \& Wardani, 2019).

\section{Keberhasilan IMD}

Pada tabel 6, nampak bahwa tingkat keberhasilan IMD dalam kategori tinggi. Hasil ini berbanding lurus dengan cakupan IMD pada bayi baru lahir provinsi Papua tahun 2019 yang juga sudah cukup tinggi, yaitu sebesar 52,77\%, sedangkan secara nasional di tahun yang sama jauh lebih tinggi, yaitu sebesar sebesar 75,58\% (Kemenkes RI, 2020).

\section{SIMPULAN}

Peran perawat dan bidan di wilayah kerja Puskesmas Distrik Kurik Kabupaten Merauke terhadap pelaksanaan IMD dalam kategori baik dan tingkat keberhasilan ibu pasca melahirkan yang melakukan IMD masuk dalam kategori tinggi.

\section{SARAN}

Mengingat pentingnya IMD, maka WHO membuat beberapa rekomendasi, yaitu: 1) kontak kulit ke kulit antara ibu dan bayi harus segera difasilitasi dan didorong secepat mungkin setelah kelahiran, 2) semua ibu harus didukung untuk IMD segera setelah lahir sampai satu jam pertama, 3) ibu harus mendapat dukungan pelatihan agar dapat melakukan IMD dan memberikan ASI dan mengatasi kesulitan yang umum terjadi.

Penelitian selanjutnya dapat dilakukan tentang tingkat pengetahuan perawat dan bidan tentang pelaksanaan IMD, dan faktor-faktor yang mempengaruhi keberhasilan pelaksanaan IMD.

\section{DAFTAR PUSTAKA}

Abie, B. M. \& Goshu, Y. A. (2019) Early Initiation of Breastfeeding and Colostrum Feeding among Mothers of Children Aged Less than 24 Months in Debre Tabor, northwest Ethiopia: A Cross-Sectional Study. BMC Research Notes, 12. doi: 10.1186/s13104-019-4094-6

Adewuyi, E. O., Zhao, Y., Khanal, V., Auta, A., Bulndi, L. B. (2017) 'Rural-Urban Differences on the Rates and Factors Associated with Early Initiation of Breastfeeding In Nigeria: Further Analysis of the Nigeria Demographic and Health Survey, 2013. International Breastfeeding Journal, 12(1), 51. DOI: 10.1186/s13006-017-0141-x

Balitbangkes. (2019). Hasil Utama Riskesdas 2018. Kementerian Kesehatan Republik Indonesia 
Fitriana, F. (2017). Pendampingan Suami pada Ibu Bersalin Berhubungan dengan Keberhasilan Inisiasi Menyusu Dini. Jurnal Ners dan Kebidanan Indonesia, 5(2), pp. 139-143. doi: 10.21927/jnki.2017.5(2).139-143

Gayatri, M. \& Dasvarma, G. L. (2020). Predictors of Early Initiation of Breastfeeding in Indonesia: A Population-Based Cross-Sectional Survey. PLOS ONE, 15(9), p. e0239446. doi: 10.1371/journal.pone.0239446

Hadisuyatmana, S., Has, E. M. M., Sebayang, S. K., Efendi, F., Astutik, E., Kuswanto, H., \& Arizona, I. K. L. Y. (2021). Women's Empowerment and Determinants of Early Initiation of Breastfeeding: A Scoping Review. Journal of Pediatric Nursing, 56, e77-e92. DOI: 10.1016/j.pedn.2020.08.004

Indra, L. \& Ruswanti, R. (2017). Peran Petugas Kesehatan terhadap Pelaksanaan IMD. Jurnal Ilmiah Ilmu Keperawatan Indonesia, 7(01), 197-204. http://journals.stikim.ac.id/index.php/jiiki/article/view/235

Irama, M., \& Muhartati, M. (2018). Faktor-Faktor yang Mempengaruhi Keberhasilan Inisiasi Menyusu Dini (IMD) di Pukesmas Lendah I Kulonprogo. : http://digilib2.unisayogya.ac.id/xmlui/handle/123456789/897

Kaban, N. B. (2018). Inisiasi Menyusu Dini. Jurnal Keluarga Sehat Sejahtera, 15(2), pp. 35-46. doi: 10.24114/jkss.v15i2.8773

Kemenkes RI. (2020). Profil Kesehata Indonesia 2019. Jakarta: Kementerian Kesehatan Republik Indonesia

Kemenpppa (2019) Profil Perempuan Indonesia 2019. Badan Pusat Statistik

Kumalasari, D., Dewinataningtyas, C. \& Rahmawati, E. (2019). Pengaruh Peran Penolong Persalinan terhadap Pelaksanaan Inisiasi Menyusu Dini di Kabupaten Kediri. Journal for Quality in Women's Health, 2(1), 7-10. https://jqwh.org/index.php/JQWH/article/view/20

Mugadza, G., Zvinavashe, M., Gumbo, F. Z., \& Pedersen, B. S. (2017). Early breastfeeding Initiation and Incidence of Neonatal Sepsis in Chipinge District Zimbabwe. International Journal of Contemporary Pediatrics, 5(1), p. 1. doi: 10.18203/2349-3291.ijcp20175564

Mujur, A., As'ad, S., \& Idris, I. (2019). Factors Affecting the Success Early Initiation of Breastfeeding (EIBF) at Puskesmas Jumpandang Baru 2014. Indian Journal of Public Health Research \& Development, 10, 949. DOI: 10.5958/09765506.2019.00829.5

Ruhayati, R., Liska, C. \& Dewi, S. S. (2019). Correlation Between Parity and The Implementation of Early Initiation of Breastfeeding (EIBF) in Ciparay Health Center at Bandung District Period March - June 2019. Third International Seminar on Global Health (3rdISGH), $3(1), 6$. http://repository2.stikesayani.ac.id/index.php/isgh3/article/view/407/365

Siahaan, J. M. \& Panjaitan, M. (2020. Persepsi Ibu Nifas tentang Peran Bidan terhadap Pelaksanaan Inisiasi Menusu Dini (IMD) di Wilayah Kerja Puskesmas Hutabaginda Tapanuli Utara Tahun 2018. Journal of Healthcare Technology and Medicine, 6(1), 70-75. http://jurnal.uui.ac.id/index.php/JHTM/article/view/667

Smith, E. R., Hurt, L., Chowdhury, R., Sinha, B., Fawzi, W., Edmond, K. M. (2017). Delayed Breastfeeding Initiation and Infant Survival: A Systematic Review and Meta-Analysis. PLoS ONE, 12(7). DOI: 10.1371/journal.pone.0180722 
Sukarti, N. N., Windiani, I. G. A. T. \& Kurniati, D. Y. (2020). Hambatan Keberhasilan Pelaksanaan Inisiasi Menyusu Dini (IMD) pada Ibu Bersalin di Rumah Sakit Umum Pusat Sanglah Denpasar. Jurnal Ilmiah Kebidanan (The Journal of Midwifery), 8(1), 40-53. file:///F:/karya tulis ilmiaaahhh/1197-2847-1-SM.pdf

Sulistianingsih, A. (2020). Faktor-Faktor yang Berpengaruh terhadap Pelaksanaan Inisiasi Menyusui Dini pada Ibu Bersalin. Jurnal Ilmiah Kesehatan, 9(1), 33-40. https://ejournal.umpri.ac.id/index.php/JIK/article/view/1013

Warsini, W. \& Wardani, Y. K. (2019). Analisis Faktor-Faktor yang Mempengaruhi Keberhasilan Inisiasi Menyusu Dini. KOSALA : Jurnal Ilmu Kesehatan, 7(1), 2935. DOI: $10.37831 /$ jik.v7i1.163

WHO (2017) Guideline: Protecting, Promoting and Supporting Breastfeeding in Facilities Providing Maternity and Newborn Services. Available at: http://whqlibdoc.who.int/publications/2011/9789241501811_eng.pdf (Accessed: 31 January 2019)

WHO (2018) Breastfeeding. Available at: https://www.who.int/news-room/facts-inpictures/detail/breastfeeding (Accessed: 24 March 2021)

WHO (2019) Early Initiation of Breastfeeding to Promote Exclusive Breastfeeding, Early Initiation of Breastfeeding to Promote Exclusive Breastfeeding. World Health Organization. Available at: http://www.who.int/elena/titles/early_breastfeeding/en/ (Accessed: 13 March 2021)

Yuliea, M. S. (2019). Pengaruh Peran Tenaga Kesehatan terhadap Kesuksesan Pelaksanaan Inisiasi Menyusu Dini di Ruang Bersalin RSU Sarah Medan Tahun 2016. Collaborative Medical Journal (CMJ), 2(1), 27-35. http://jurnal.univrab.ac.id/index.php/cmj/article/view/640 